\title{
Sistema de integração lavoura-pecuária: desempenho e qualidade da carcaça de novilhos superprecoces terminados em pastagem de aveia e azevém manejada sob diferentes alturas
}

\author{
Crop-livestock integration system: performance and carcass quality of superprecoce beef steers finished \\ in oat and ryegrass pasture managed under different heights
}

\author{
Marília Lazzarotto Terra Lopes ${ }^{\mathrm{I}}$ Paulo César de Faccio Carvalho ${ }^{\mathrm{II}}$ Ibanor Anghinoni ${ }^{\mathrm{I}}$ \\ Davi Teixeira dos Santos ${ }^{\mathrm{I}}$ Fernando Kuss $^{\mathrm{I}}$ Fabiana Kellermann de Freitas $^{\mathrm{I}}$ \\ João Paulo Cassol Flores ${ }^{I}$
}

\section{RESUMO}

O objetivo do experimento foi avaliar o desempenho e a qualidade da carcaça de novilhos superprecoces submetidos a alturas de manejo do pasto de aveia e azevém $(10,20,30$ e $40 \mathrm{~cm})$, suplementado no terço final do ciclo de pastejo. Animais jovens com idade média de dez meses e peso inicial de $190 \mathrm{~kg}$ foram distribuídos num delineamento experimental de blocos ao acaso, com três repetições. As ofertas de forragem para os tratamentos 10, 20, 30 e $40 \mathrm{~cm}$ foram respectivamente, 8,8, 14,7, 29,0 e 48,9kg de matéria seca $100 \mathrm{~kg}$ de peso vivo-1 $(P V)$. O ganho de peso por hectare foi superior nos tratamentos com menor altura, em decorrência da maior carga animal, sendo obtidos para 10 , 20, 30 e 40cm de altura ganhos por área de 529,7, 489,5, 320,9 e 201,6kg de $P V h^{-1}$, respectivamente. O ganho médio diário e peso ao abate apresentaram resposta quadrática $(P<0,05)$ conforme o incremento na altura do pasto. A deposição de gordura apresentou média de $3,8 \mathrm{~mm}$ e o rendimento médio de carcaça fria foi de 53,3\% $(P>0,05)$. Novilhos superprecoces atingiram peso de abate e grau de acabamento adequados quando terminados em pastagem cultivada de inverno e suplementados no terço final do ciclo de pastejo. $O$ melhor ganho médio diário foi obtido em altura entre 25 a 30cm, e maior produção por área quando a pastagem foi manejada a $10 \mathrm{~cm}$ de altura.

Palavras-chave: carga animal, conformação da carcaça, ganho de peso, grau de acabamento, oferta de forragem, peso de abate.

\section{ABSTRACT}

This trial aimed at evaluating the performance and carcass quality of superprecoce steers grazing oat and annual ryegrass pastures managed at 10, 20, 30 and $40 \mathrm{~cm}$ height, and supplemented at the final third of the grazing cicle. Young animals with 10 months on average and initial weight of $190 \mathrm{~kg}$ were distributed in a randomized block design with three replicates. The herbage allowances were 8.8, 14.7, 29.0 and $48.9 \mathrm{~kg}$ of dry matter $100 \mathrm{~kg}$ of live weight ${ }^{-1}(\mathrm{LW})$, respectively for the treatments 10,20,30 and $40 \mathrm{~cm}$. The live weight gain per hectare was superior in treatments with lower heights, due to the increased stocking rate, being 529.7, 489.5, 320.9 and $201.6 \mathrm{~kg}$ of $\mathrm{LW}$, respectively for $10,20,30$ and $40 \mathrm{~cm}$ height. The average daily gain and slaughter weight increased with pasture height being fitted by a quadratic model $(P<0.05)$. The fat deposition and the medium dressing of cold carcass averaged $3.8 \mathrm{~mm}$ and $53.3 \%$, respectively $(P>0.05)$. Superprecoce steers reached slaughter weight and adequately finishing degree when finished in winter cultivated pasture supplemented in final third of grazing cicle. Better individual animal performance was obtained when pasture height ranges from 25 to $30 \mathrm{~cm}$, and animal production per hectare when the pasture was managed at $10 \mathrm{~cm}$ height.

Key words: carcass conformation, finishing degree, herbage, allowance, slaughter weight, stocking rate, live weight gain.

\section{INTRODUÇÃO}

A região do planalto do Rio Grande do Sul é uma área que ocupa destaque na agricultura do Estado por apresentar condições de clima e solo bastante propícias para o desenvolvimento da atividade agrícola e pecuária. A agricultura nesta região vem sendo explorada ao longo dos anos de forma bastante intensiva durante o verão, sendo cultivados aproximadamente 5 milhões de hectares com soja e milho. No entanto, no inverno, muitas dessas áreas

IUniversidade Federal do Rio Grande do Sul (UFRGS), Porto Alegre, RS, Brasil.

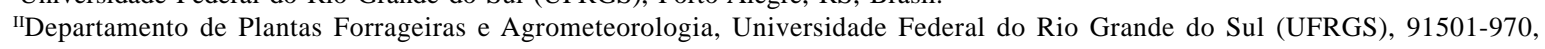

Porto Alegre, RS, Brasil. E-mail: paulocfc@ufrgs.br. Autor para correspondência. 
permanecem sem utilização, sendo utilizados somente 18\% da área cultivada no verão com os cultivos de trigo, aveia, cevada e centeio (IBGE, 1996), ficando aproximadamente 4 milhões de hectares sem geração de renda.

O sistema de integração lavoura-pecuária, com a alternância temporária (rotação) do cultivo de grãos com o pastejo de animais em pastagens de gramíneas e/ou leguminosas, pode ser utilizado de distintas maneiras, dependendo de interesses individuais (MORAES et al., 1998). A integração lavoura-pecuária torna-se, cada vez mais, uma das alternativas mais promissoras para desenvolver sistemas de produção menos intensivos no uso de insumos e, portanto, mais sustentáveis econômica e ecologicamente no tempo. Segundo MORAES et al. (2002), o principal entrave para a adoção do sistema integrado de produção lavoura-pecuária seria uma possível compactação do solo provocada pelo pisoteio dos animais em pastejo. Conforme esses autores, o estudo do efeito da entrada de animais em áreas agrícolas e sua ação compactadora, na opinião dos produtores, deveriam ser priorizados pela pesquisa, em função da hipótese de haver comprometimento do rendimento de grãos nessas áreas, no sistema de semeadura direta. Entretanto, TREIN et al. (1991), após aplicarem alta lotação em curto espaço de tempo (200 novilhas ha-1 por 36 horas), num Argissolo Vermelho cultivado com aveia e trevo, observaram aumento na densidade e resistência do solo ao penetrômetro, com conseqüente diminuição da macroporosidade e infiltração de água no solo, somente na camada superficial $(0-7,5 \mathrm{~cm})$, sem alterações nas camadas subsuperficiais. BERTOL et al. (1998), em pastagem natural do Rio Grande do Sul, observou significativa diminuição da infiltração de água no solo e tendências de aumento da densidade e diminuição da porosidade somente em baixas ofertas de forragem (4,0 e 8,0\% do peso vivo dos animais), não havendo efeito em ofertas de forragem mais altas (12,0 e 16,0\% do peso vivo). Também BOENI et al. (1995), avaliando a camada 0$10 \mathrm{~cm}$ de um solo Franco-Siltoso em área de pastagem de aveia e azevém com carga animal moderada, não encontraram efeito do pisoteio animal em pastejo contínuo de junho a outubro. Esses resultados ratificam a idéia de que a terminação de novilhos em sistema integrado com a produção de grãos é uma alternativa bastante plausível do ponto de vista da otimização do uso da terra, desde que a utilização das pastagens ocorra de forma adequada ao sistema como um todo.

O período crítico para a produção de bovinos de corte no Sul do país é o de outono-inverno, pois é uma época de baixa disponibilidade e qualidade das pastagens naturais, o que resulta em baixos índices de produtividade do rebanho bovino gaúcho. Portanto, o uso de pastagens hibernais com elevado valor nutritivo e alto potencial produtivo é necessário para tornar viável a terminação de bovinos superprecoces (14 meses de idade) durante a entressafra, aumentando a rentabilidade das empresas rurais, com a redução do ciclo de produção. É de fundamental importância que estas pastagens sejam utilizadas da maneira mais eficiente possível. Nesse aspecto, o estabelecimento, a adubação, o manejo da pastagem e a escolha da categoria animal têm grande importância para o sucesso e a lucratividade do sistema (SANTOS et al., 2004). A terminação de novilhos superprecoces, num único inverno, permite que áreas usualmente destinadas à agricultura não sejam ocupadas pela pecuária no verão, tornando a adoção desta técnica de manejo adequada para os produtores de cereais. Além disso, é necessário proporcionar uma carcaça que venha a satisfazer às exigências de comercialização, com peso e acabamento adequados à categoria referida (de 160 a 250kg e 3 a $6 \mathrm{~mm}$, respectivamente). Para isso, práticas, como a suplementação a pasto, podem ser utilizadas de forma estratégica durante a fase de terminação (CATON \& DHUYVETTER, 1997). Fornecendo suplementos energéticos (milho ou casca de soja; 0,9\% do peso vivo) para novilhas em pastagem de aveia e azevém, SANTOS et al. (2005) verificaram incremento médio de $61,7 \%$ no desempenho individual dos animais no terço final de utilização da pastagem, o que resultou em condição corporal final superior para animais suplementados em relação àqueles mantidos exclusivamente a pasto.

O presente trabalho teve como objetivo avaliar o desempenho e as características de carcaça de novilhos superprecoces terminados em pastagem de aveia e azevém manejada em diferentes alturas, num sistema de integração lavoura-pecuária.

\section{MATERIAL E MÉTODOS}

O experimento foi conduzido em área pertencente à fazenda Espinilho, localizada no município de Tupanciretã, região fisiográfica planalto médio do Rio Grande do Sul (RS). O solo é classificado como latossolo vermelho distroférrico, com coloração vermelho-escura e textura muito argilosa (mais de $60 \%$ de argila). Aárea experimental totaliza 21ha subdivididos em 12 piquetes (unidades experimentais). A pastagem de aveia preta (Avena strigosa Schreb) e azevém (Lolium multiflorum Lam) foi implantada em 10 de maio de 2004, logo após a colheita da soja. Foram utilizados $100 \mathrm{~kg} \mathrm{ha}^{-1}$ de sementes de aveia preta e $25 \mathrm{~kg}$ 
ha ${ }^{-1}$ de sementes de azevém, mais adubação com base na análise do solo. Em cobertura, foram aplicados $66 \mathrm{~kg}$ ha $^{-1}$ de $\mathrm{N}$ na forma de uréia, 40 dias após a semeadura. Os tratamentos impostos foram quatro alturas de manejo do pasto: 10, 20, 30 e 40cm, obtidas através da aplicação de diferentes cargas animais. Foram utilizados animais com aproximadamente dez meses de idade, machos castrados oriundos de cruzamentos entre as raças Angus, Hereford e Nelore, sem grau de sangue definido e com peso vivo médio inicial de $190 \mathrm{~kg}$. Foram everminados com aplicação de ivermectina na dosagem de 5,0ml/animal e identificados com brinco ao início do experimento. A altura do pasto foi medida com um bastão graduado (Sward stick), cujo marcador corre por uma "régua” até tocar a primeira lâmina foliar, procedendose então à leitura da altura, em centímetros (BARTHRAM, 1981). O controle da altura do pasto foi feito em intervalos de 15 dias aproximadamente, totalizando sete avaliações. A leitura foi realizada em 100 pontos dentro de cada piquete, em caminhamento aleatório, a fim de definir a altura média da pastagem. $\mathrm{O}$ pastejo foi realizado pelo método contínuo com lotação variável, composta por três animais-teste por piquete e animais reguladores, através da técnica put-and-take descrita por MOTT \& LUCAS (1952). O início do pastejo ocorreu no dia 12 de julho, momento em que a altura média da pastagem era de 23,2cm (em torno de $1.500 \mathrm{~kg}$ ha ${ }^{-1}$ de matéria seca) e se estendeu até 14 de novembro de 2004, totalizando 125 dias, quando os animais foram retirados e abatidos. Os animais foram suplementados com ração comercial energética com $12 \%$ de proteína bruta (PB) e 72\% de nutrientes digestíveis totais (NDT), na proporção de $0,8 \%$ do PV (com base no material oferecido) nos últimos 44 dias de avaliação, a fim de proporcionar maior grau de acabamento aos novilhos em todos os tratamentos.

Ao longo do período de pastejo, foram realizadas quatro pesagens, com jejum prévio de sólidos e líquidos de 12 horas, para avaliação do ganho de peso médio diário (GMD). A carga animal média, expressa em kg de PV ha ${ }^{-1}$ dia $^{-1}$, foi calculada para cada unidade experimental, pela adição do peso médio dos animaisteste, com o peso médio de cada animal regulador, multiplicado pelo número de dias em que este permaneceu na pastagem, dividido pelo número total de dias de pastejo. $\mathrm{O}$ ganho de peso total por hectare foi obtido pela multiplicação da taxa de lotação média ( $\mathrm{n}^{\mathrm{o}}$ de animais ha ${ }^{-1}$ dia $^{-1}$ ) pelo GMD dos animais-teste e pelo número de dias de pastejo. $\mathrm{O}$ escore de condição corporal dos novilhos foi atribuído em cada pesagem por observação visual, conforme a metodologia descrita por LOWMAN et al. (1973), numa escala de 1,0 (muito magro) a 5,0 (muito gordo). Para condição corporal ao abate, considerou-se a última avaliação, realizada por ocasião do embarque dos animais para o frigorífico.

O abate e as avaliações de carcaça foram realizados nas dependências do frigorífico Frigonal, localizado no município de Montenegro - RS, distante aproximadamente $400 \mathrm{~km}$ da fazenda. Os animais foram transportados de caminhão e, ao chegar ao frigorífico, permaneceram em quarentena por um período mínimo de 12 horas, com jejum de sólidos e sob observação de responsáveis pela inspeção sanitária. O abate ocorreu conforme o fluxo normal do frigorífico. As carcaças foram identificadas, lavadas e resfriadas a $-2^{\circ} \mathrm{C}$ por 24 horas. Decorrido este período, as mesmas foram pesadas para obtenção do peso e determinação do rendimento de carcaça fria. Na meia carcaça direita, realizaram-se as avaliações das medidas de desenvolvimento (comprimento da carcaça e braço, e perímetro de braço) e da conformação, esta última conforme a metodologia proposta por MÜLLER (1987). Ainda, na altura da 12a costela, foi realizado o corte para a avaliação da espessura de gordura de cobertura. A meia carcaça esquerda foi dividida nos cortes dianteiro, costilhar (ponta de agulha) e serrote (traseiro especial), os quais foram pesados para posterior cálculo da participação percentual em relação à meia carcaça.

O delineamento experimental utilizado foi o de blocos ao acaso, com três repetições de área por tratamento (piquetes). Os resultados foram submetidos à análise de variância e regressão até terceira ordem, ao nível de 5\%, através do uso do aplicativo computacional SAS (1997). O peso vivo inicial (PI) foi utilizado como covariável no modelo estatístico para todas as variáveis em estudo. Sempre que a funçãoresposta foi significativa $(\mathrm{P}<0,05)$, optou-se por apresentar os resultados pela equação de regressão de maior coeficiente de determinação $\left(\mathrm{R}^{2}\right)$, tendo em vista a possibilidade de a regressão estimar as variáveisresposta em valores de altura do pasto intermediários àqueles utilizados como tratamentos. Para as variáveis que não se ajustaram a um modelo de regressão, realizou-se análise de variância e teste $\mathrm{F}$ e, quando detectadas diferenças ao nível de 5\%, as médias foram comparadas pelo teste Tukey a este mesmo nível de significância.

\section{RESULTADOS E DISCUSSÃO}

As ofertas de forragem para 10, 20, 30 e $40 \mathrm{~cm}$ de altura foram de 8,8, 14,7, 29,0 e 48,9kg MS para cada $100 \mathrm{~kg} \mathrm{PV} \mathrm{dia}{ }^{-1}$, respectivamente (Figura 1). Para potencializar o desempenho individual dos animais, considerando-se a literatura disponível em termos de 


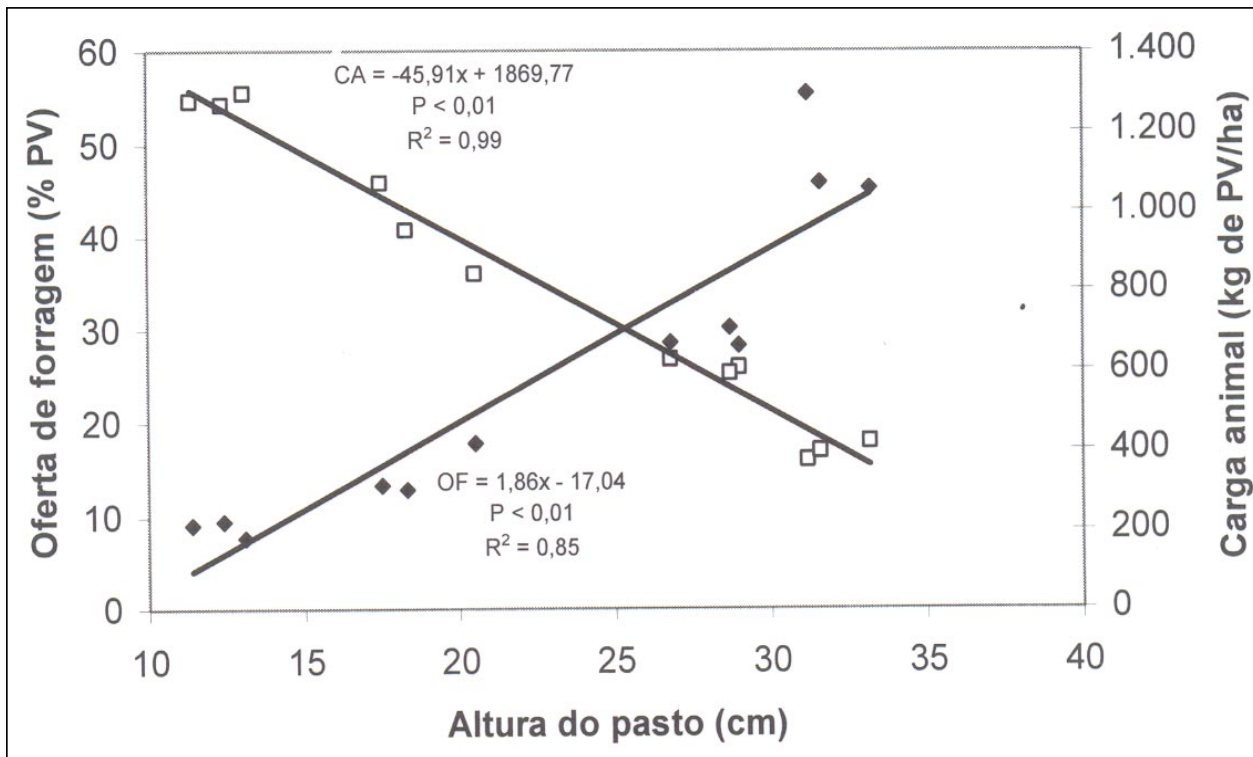

Figura 1 - Relações entre altura do pasto (AP) a oferta de forragem (OF) e carga animal (CA) em pastagem de aveia e azevém manejada sob diferentes alturas no desempenho de novilhos de corte.

oferta de forragem (MOOJEN \& MARASCHIN, 2002; HODGSON, 1990), esses valores podem ser considerados insuficientes na altura de $10 \mathrm{~cm} \mathrm{e}$ excessivamente altos nas alturas de 30 e $40 \mathrm{~cm}$. Na medida em que foram aumentadas as alturas de pastejo, houve incremento no desempenho individual até a altura $25 \mathrm{~cm}$ (Figura 2), com GMD estimado de 1,225kg animal $^{-1} \mathrm{dia}^{-1}$. Em alturas do pasto entre 20 e $30 \mathrm{~cm}$, a curva de resposta estima valores de desempenho superiores a $1,0 \mathrm{~kg}$ animal ${ }^{-1} \mathrm{dia}^{-1}$, o que representa uma velocidade de ganho de peso interessante para o propósito da terminação dos novilhos em condições adequadas ao final do ciclo da pastagem de inverno. $\mathrm{O}$ menor desempenho na altura de $10 \mathrm{~cm}$ é, claramente, função da oferta de forragem limitante, pois além do valor em si (8,8kg MS para cada $100 \mathrm{~kg}$ PV), esta altura de manejo pode comprometer a profundidade e, conseqüentemente, a massa do bocado, componentes essenciais na composição do consumo diário de MS. Já a tendência de menor GMD em maiores alturas

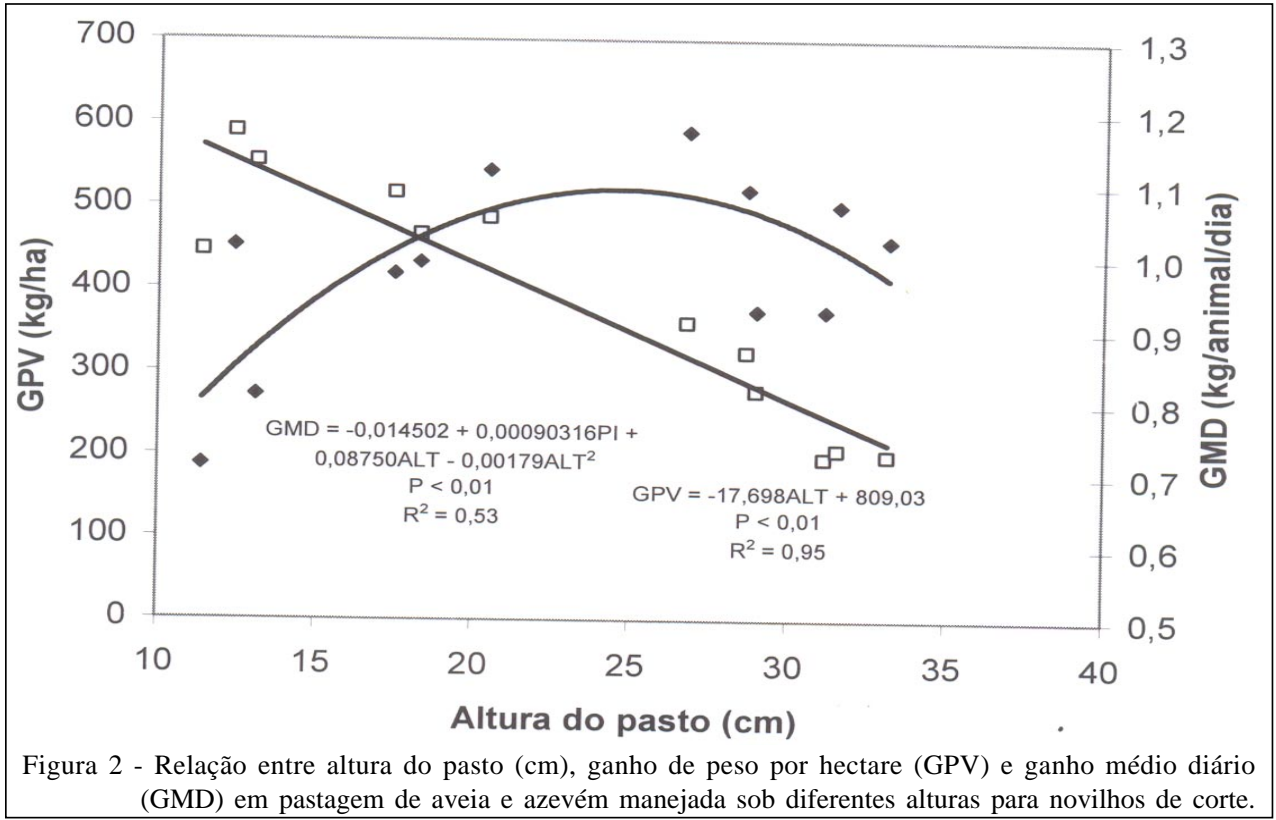

Ciência Rural, v.38, n.1, jan-fev, 2008. 
provavelmente está relacionada a alterações na estrutura da pastagem, que podem ocasionar diminuição no consumo pela redução na profundidade do bocado e aumento no tempo dispendido para procura, apreensão e manipulação da forragem disponível (CARVALHO et al., 1999). O ganho de 0,855kg.animal.dia ${ }^{-1}$ obtido com o tratamento de menor altura $(10 \mathrm{~cm})$ foi maior do que o observado por AGUINAGA et al. (2004) (0,730 kg dia $\left.{ }^{-1}\right)$, na mesma área e sob mesmo protocolo experimental, possivelmente em função de um efeito aditivo da suplementação no período final sobre o consumo total de MS, além de efeitos inerentes ao ano de avaliação. A figura 2 ilustra que o GPV apresentou resposta linear negativa, sendo que, à medida que foi aumentada a altura de manejo do pasto, o GPV decresceu $(\mathrm{P}<0,05)$. Como a variação no GMD observado foi relativamente baixa, de 0,855 a $1,061 \mathrm{~kg}$, o maior GPV observado no tratamento $10 \mathrm{~cm}$ foi, sobretudo, resposta da aplicação de uma maior carga animal (CA), conforme a figura 1. Esta, por sua vez, apresentou resultado semelhante ao do ganho de peso por área (Figura 2), com decréscimo de seus valores quando do aumento da altura do pasto. De acordo com as equações de regressão, cada cm a mais na altura do pasto correspondeu a um decréscimo de $45,91 \mathrm{~kg}$ na CA e de 17,69kg no GPV. Embora o tratamento $10 \mathrm{~cm}$ de altura tenha obtido uma produção em $\mathrm{kg}$ de $\mathrm{PV} \mathrm{ha}{ }^{-1}$ superior aos demais, foi no tratamento de $30 \mathrm{~cm}$ que os animais atingiram os maiores valores de peso vivo ao abate $(327,5 \mathrm{~kg})$, indicando maior segurança para utilização em sistemas de integração lavoura-pecuária, onde não seja necessário destinar áreas de verão para terminação destes animais e, conseqüentemente, reduzir a área destinada à agricultura, já que a terminação é viabilizada em um único ciclo de pastagem de inverno.

Ainda com relação ao ganho de PV por área, o elevado nível de produção obtido no tratamento de $10 \mathrm{~cm}$ de altura (Figura 2) deve ser analisado com cautela, em se tratando de um sistema de integração lavourapecuária. Neste caso, importantes alterações podem ocorrer do ponto de vista físico do solo, dado que este foi o tratamento que apresentou menor massa de forragem remanescente $\left(1.686 \mathrm{~kg} \mathrm{ha}^{-1}\right.$ de MS). Além disso, quando este sistema é utilizado em áreas com agricultura no sistema de semeadura direta, tais níveis de massa podem não ser os mais adequados para fornecer palhada suficiente para a cultura subseqüente. Um nível de palhada residual próximo a $3.000 \mathrm{~kg}$ de $\mathrm{MS} \mathrm{ha}^{-1}$ tem sido sugerido como sendo o ponto de equilíbrio do sistema (AGUINAGA et al., 2004). No presente estudo, a pastagem manejada a $30 \mathrm{~cm}$ de altura apresentou massa de forragem residual de $2.911 \mathrm{~kg}$ de $\mathrm{MS} \mathrm{ha}^{-1}$.
Na tabela 1, observa-se que o peso ao abate (PA) aumentou com o incremento da altura do pasto até $30 \mathrm{~cm}$, acompanhando a resposta quadrática do desempenho individual dos novilhos (GMD) (Figura 2). As correlações da altura do pasto com o peso de abate $(0,55 ; \mathrm{P}=0,0603)$ e com o ganho de peso $(0,61$; $\mathrm{P}=0,0362)$ foram positivas. $O$ peso de carcaça fria não se ajustou ao modelo quadrático, mas apresentou a mesma tendência de estabilização ou pequena queda dos valores a partir da altura de $30 \mathrm{~cm}$. As demais variáveis expostas na tabela 1 não se ajustaram aos modelos de regressão de primeira até terceira ordem, e as médias não diferiram entre si pela análise de variância (P>0,05). A condição corporal (CC) ao abate dos novilhos apresentou média de 3,2 pontos, considerados "regular". No entanto, a espessura de gordura subcutânea (EGS) permaneceu dentro dos padrões atualmente estabelecidos pelos frigoríficos do Rio Grande do Sul (3 a 6mm), apresentando média de 3,8mm entre os tratamentos. A EGS estando dentro desta faixa preconizada pelos frigoríficos reduz as perdas por desidratação durante o resfriamento, o que proporciona maior rendimento de carcaça e, conseqüentemente, maior produção de carne.

Observa-se ainda, na tabela 1 , que os animais apresentaram rendimento médio de carcaça fria de 54,6\%, considerado normal para esta categoria. Este rendimento foi superior ao obtido por RESTLE \& VAZ (1997), de 51,1\%, com novilhos Hereford abatidos aos 14 meses em confinamento, com peso de carcaça e espessura de gordura superiores aos deste estudo (189,5kg e 5,5mm, respectivamente). Quanto à conformação (CONF), os animais apresentaram valor médio de 9,9 pontos. A conformação é uma característica de expressão muscular da carcaça e significa que animais com maior conformação apresentam maior rendimento de músculo. Isso se reflete, para o frigorífico, em menor custo de produção por kg de carne comercializada e, ao consumidor, em maior porção comestível na compra na gôndola de determinado corte muscular, especialmente quando da presença de ossos.

Os valores de peso e participação percentual dos cortes comerciais na carcaça são características de interesse dos frigoríficos na avaliação do valor do produto adquirido, uma vez que tanto o mercado interno como o externo exigem determinados tamanhos de músculo que compõem estes cortes (KUSS et al., 2005). Na tabela 2, podem ser observados os resultados para os cortes primários em valor absoluto e em relação à carcaça fria. A altura do pasto não exerceu efeito $(\mathrm{P}>0,05)$ sobre o valor absoluto do costilhar (média de 23,7kg), diferente do observado nos cortes serrote e dianteiro, em que ambos apresentaram comportamento 
Tabela 1 - Médias, erros-padrão (EP) e equações de regressão (ER) para peso de abate (PA, kg), condição corporal ao abate (CC, pontos), peso (PCF, kg) e rendimento de carcaça fria (RCF, \%), espessura de gordura subcutânea (EGS, mm) e EGS por 100kg de carcaça fria (EGS/100, mm), conformação da carcaça (CONF, pontos), comprimento de carcaça (CCARC, cm) e braço (CBRA, cm), perímetro de braço (PBRA, cm) da carcaça de novilhos superprecoces mantidos em pastagem de aveia e azevém manejada sob diferentes alturas.

\begin{tabular}{|c|c|c|c|c|c|}
\hline \multirow{2}{*}{ Características } & \multicolumn{4}{|c|}{ Altura do pasto, cm } & \multirow{2}{*}{ ER } \\
\hline & 10 & 20 & 30 & 40 & \\
\hline PI & $198,7 \pm 5,9$ & $191,7 \pm 5,9$ & $192,3 \pm 5,9$ & $196,3 \pm 5,9$ & -- \\
\hline PA & $301,0 \pm 5,4$ & $321,7 \pm 5,4$ & $327,5 \pm 5,4$ & $320,4 \pm 5,3$ & 1 \\
\hline CC & $3,0 \pm 0,1$ & $3,3 \pm 0,1$ & $3,2 \pm 0,1$ & $3,3 \pm 0,1$ & 2 \\
\hline PCF & $164,3 \pm 2,8$ & $169,3 \pm 2,7$ & $172,0 \pm 2,7$ & $171,3 \pm 2,7$ & 3 \\
\hline RCF & $54,6 \pm 1,0$ & $52,7 \pm 1,0$ & $52,5 \pm 1,0$ & $53,5 \pm 1,0$ & 4 \\
\hline EGS & $3,2 \pm 0,5$ & $4,1 \pm 0,5$ & $4,4 \pm 0,5$ & $3,4 \pm 0,5$ & 5 \\
\hline EGS/100 & $2,0 \pm 0,3$ & $2,4 \pm 0,3$ & $2,5 \pm 0,3$ & $2,0 \pm 0,3$ & 6 \\
\hline CONF & $9,4 \pm 0,3$ & $10,2 \pm 0,3$ & $9,6 \pm 0,3$ & $10,3 \pm 0,3$ & 7 \\
\hline CCARC & $114,4 \pm 0,8$ & $113,9 \pm 0,8$ & $113,5 \pm 0,8$ & $113,5 \pm 0,8$ & 8 \\
\hline CBRA & $37,9 \pm 0,9$ & $36,6 \pm 0,8$ & $38,5 \pm 0,8$ & $39,2 \pm 0,8$ & 9 \\
\hline PBRA & $32,5 \pm 0,5$ & $34,0 \pm 0,5$ & $33,6 \pm 0,5$ & $34,2 \pm 0,5$ & 10 \\
\hline
\end{tabular}

1. $\mathrm{Y}=-18,04314+1,11270 \mathrm{PI}^{*}+10,84257 \mathrm{ALT}^{* *}-0,22143 \mathrm{ALT}^{2}\left(\mathrm{P}=0,0307 ; \mathrm{R}^{2}=0,6517\right) ; 2 . \mathrm{Y}=3,2 ; 3 . \mathrm{Y}=81,17568+0,40280 \mathrm{PI}+$ 0,40801ALT $\left(\mathrm{P}=0,0742 ; \mathrm{R}^{2}=0,4389\right) ; 4 . \mathrm{Y}=53,3 ; 5 . \mathrm{Y}=3,8 ; 6 . \mathrm{Y}=2,2 ; 7 . \mathrm{Y}=9,9 ; 8 . \mathrm{Y}=114,0 ; 9 . \mathrm{Y}=38,4 ; 10 . \mathrm{Y}=33,6$.

* Peso inicial; ** Altura do pasto.

quadrático com o aumento da altura do pasto $(\mathrm{P}<0,05)$. Este comportamento foi similar ao encontrado para o GMD e peso de abate dos animais. Com os valores expressos em percentagem de carcaça, os resultados obtidos neste experimento são similares aos encontrados por RESTLE \& VAZ (1997) (48,6, 14,0, $37,3 \%$ vs $48,8,14,1$ e $37,1 \%$, respectivamente para serrote, costilhar e dianteiro), trabalhando com novilhos inteiros vs castrados, abatidos aos 14 meses. A similaridade desses resultados pode ser importante para consolidar uma ferramenta de estimação de tamanho de cortes comerciais de novilhos superprecoces com base no peso de abate ou peso de carcaça fria.

\section{CONCLUSÕES}

O desempenho individual de novilhos de corte superprecoces em pastagem de aveia e azevém é otimizado com o aumento da altura do pasto até valores entre 25 e $30 \mathrm{~cm}$, com ganho de peso por animal superior a $1,0 \mathrm{~kg} \mathrm{dia}^{-1}$. A produção de peso vivo por hectare e a carga animal aumentam linearmente com a redução da altura de pastejo até $10 \mathrm{~cm}$.

O peso de abate, de carcaça fria e dos cortes primários serrote e dianteiro atingem valores máximos com altura do pasto próxima a $30 \mathrm{~cm}$, e sendo que o grau de acabamento de animais superprecoces

Tabela 2 - Médias, erros-padrão (EP) e equações de regressão (ER) dos cortes primários da carcaça de novilhos superprecoces mantidoslem pastagem de aveia e azevém manejada sob diferentes alturas.

\begin{tabular}{lcccc}
\hline & \multicolumn{4}{c}{ Altura do pasto, cm } \\
\cline { 2 - 5 } Características & 10 & 20 & 30 & 40 \\
Serrote, kg & $80,7 \pm 1,4$ & $81,4 \pm 1,4$ & $83,7 \pm 1,4$ & $83,1 \pm 1,4$ \\
Costilhar, kg & $22,4 \pm 0,7$ & $23,8 \pm 0,7$ & $24,5 \pm 0,7$ & $24,4 \pm 0,7$ \\
Dianteiro, kg & $61,2 \pm 0,9$ & $63,2 \pm 0,9$ & $64,0 \pm 0,9$ & $63,8 \pm 0,9$ \\
Serrote, \% & $49,2 \pm 0,3$ & $48,3 \pm 0,3$ & $48,6 \pm 0,3$ & $48,5 \pm 0,3$ \\
Costilhar, \% & $13,5 \pm 0,3$ & $14,1 \pm 0,3$ & $14,3 \pm 0,3$ & $14,2 \pm 0,3$ \\
Dianteiro, \% & $37,3 \pm 0,3$ & $37,5 \pm 0,3$ & $37,1 \pm 0,3$ & $37,2 \pm 0,3$ \\
\hline
\end{tabular}

1. $\mathrm{Y}=37,60472+0,21089 \mathrm{PI}+0,15398 \mathrm{ALT}\left(\mathrm{P}=0,0428 ; \mathrm{R}^{2}=0,5035\right) ; 2 . \mathrm{Y}=23,7 ; 3 . \mathrm{Y}=30,88543+0,14974 \mathrm{PI}+0,12955 \mathrm{ALT}(\mathrm{P}=$ 0,$\left.00671 ; R^{2}=0,4514\right) ; 4 . Y=48,7 ; 5 . Y=14,0 ; 6 . Y=37,3$.

Ciência Rural, v.38, n.1, jan-fev, 2008. 
terminados nesta estratégia de terminação encontrase dentro dos padrões preconizados pelos frigoríficos.

O manejo do pasto com altura próxima a 30cm permite, além da maximização do desempenho individual dos animais, a obtenção de um adequado nível de palhada residual para o cultivo de verão subseqüente.

\section{REFERÊNCIAS}

AGUINAGA, A.A.Q et al. Produção de novilhos superprecoces em sistema de integração lavoura-pecuária: efeito de diferentes alturas de manejo da pastagem de inverno no rendimento e conformação das carcaças. In. REUNIÃO ANUAL DA SOCIEDADE BRASILEIRA DE ZOOTECNIA, 41., 2004, Campo Grande, MS. Anais... Campo Grande: SBZ, 2004. CD room.

BARTHRAM, G.T. Sward structure and the depth of the grazed horizon. Grass and Forage Science, v.36, n.2, p.130-131, 1981.

BERTOL, I. et al. Propriedades físicas do solo relacionadas a diferentes níveis de oferta de forragem numa pastagem natural. Pesquisa Agropecuária Brasileira, v.33, n.5, p.779-786, 1998.

BOENI, M. et al. Efeito do pisoteio animal durante o pastejo de inverno sobre algumas propriedades físicas do solo. In: CONGRESSO BRASILEIRO DE CIÊNCIA DO SOLO, 25., 1995, Viçosa (MG). Resumos expandidos... Viçosa (MG): Sociedade Brasileira de Ciência do Solo, 1995. V.1, p.160161 .

CARVALHO, P.C.F. et al. O processo de pastejo: desafios da procura e apreensão da forragem pelo herbívoro. In: REUNIÃO ANUAL DA SOCIEDADE BRASILEIRA DE ZOOTECNIA, 36., 1999, Porto Alegre. Anais... Porto Alegre: SBZ, 1999. V.2, p.253-268.

CATON, J.S.; DHUYVETTER, D.V. Influence of energy supplementation on grazing ruminants: requirements and responses. Journal of Animal Science, v.75, p.533-542, 1997.

HODGSON, J. Grazing management: science into pratice. New York: Longman Scientific and Technial, 1990. 203p.

IBGE. Instituto Brasileiro de Geografia e Estatística. Anuário Estatístico do Brasil. Rio de Janeiro, 1996. V.56.

KUSS, F. et al. Características da carcaça de vacas de descarte de diferentes grupos genéticos terminadas em confinamento com distintos pesos. Revista Brasileira de Zootecnia, v.34, n.3, p.915-925, 2005.

LOWMAN, B.G. et al. Condition scoring beef cattle. Edinburgh: East of Scotland College of Agriculture, 1973. 8p.

MOOJEN, E.L.; MARASCHIN, G.E. Potencial produtivo de uma pastagem nativa do Rio Grande do Sul submetida a níveis de oferta de forragem. Ciência Rural, v.32, n.1, p.127-132, 2002

MORAES, A. et al. Integração lavoura-pecuária no sul do Brasil. In: ENCONTRO DE INTEGRAÇÃO LAVOURA-PECUÁRIA NO SUL DO BRASIL, 2002, Pato Branco. Anais... Pato Branco: CEFET - PR, 2002. p.3-42.

MORAES, A. et al. Lavoura-pecuária em sistemas integrados na pequena propriedade. In: ENCONTRO LATINOAMERICANO SOBRE PLANTIO DIRETO NA PEQUENA PROPRIEDADE, 3., 1998, Pato Branco. Anais... Pato Branco: CEFET - PR, 1998. CD-ROOM.

MOTT, G.O.; LUCAS, H.L. The design, conduct and interpretation of grazing trials on cultivated and improved pastures. In: INTERNATIONAL GRASSLAND CONGRESS, 6., 1952, Pensylvania. Proceedings... Pensylvania: State College, 1952. p.1380-1395.

MÜLLER, L. Normas para a avaliação de carcaças em concursos de carcaça de novilhos. 2.ed. Santa Maria: UFSM, 1987. 31p.

RESTLE, J.; VAZ, F. Aspectos quantitativos da carcaça de machos Hereford, inteiros e castrados, abatidos aos quatorze meses. Pesquisa Agropecuária Brasileira, v.32, n.1, p.1091-1095, 1997.

SANTOS, D.T. et al. Suplementos energéticos para recria de novilhas de corte em pastagens anuais. Desempenho animal. Revista Brasileira de Zootecnia, v.34, n.1, p.209-219, 2005.

SANTOS, D.T. et al. Suplementos energéticos para recria de novilhas de corte em pastagens anuais. Análise econômica. Revista Brasileira de Zootecnia, v.33, n.6, p.2359-2368, 2004. (supl. 3).

SAS INSTITUTE. User's guide statistics. 4.ed. Cary, NC, 1997. V.2, 943p.

TREIN, C.R. et al. Métodos de preparo do solo na cultura do milho e ressemeadura do trevo, na rotação aveia + trevo/milho, após pastejo intensivo. Revista Brasileira de Ciência do Solo, v.15, n.1, p.105-111, 1991. 